\title{
Composição e moralidade do melhor dos mundos em Leibniz ${ }^{1}$
}

\author{
Composition and morality about \\ the best of all possible worlds in Leibniz
}

\author{
André Chagas Ferreira de Souza \\ Universidade Federal de Lavras (UFLA) \\ Orcid 0000-0001-7654-6104 \\ chagas.andre@ufla.br
}

Resumo: O objetivo deste artigo é abordar a filosofia de Leibniz a respeito do processo que culminou na sua tese sobre o melhor dos mundos elaborado por Deus. Na sua fase de juventude, o filósofo considerou que a construção da obra divina se deu a partir da combinação de partes elementares, denominadas requisitos. Todavia, esse simples modelo de arquitetura aproximava Leibniz perigosamente do espinosismo, de modo que o fato de Deus ser a sede e onde se daria a combinação dos requisitos de maneira exclusiva o colocavam como única fonte da realidade e de todos os fatos no mundo, inclusive daquilo que existe de mal. Evitar esse problema teológico motivou Leibniz na elaboração de uma ontologia mais sofisticada, no bojo da

$1 \quad$ Este artigo se originou a partir de uma profunda revisão de parte dos resultados de um antigo projeto, denominado Liberdade em Leibniz. Novas perspectivas sobre o tema, releituras dos textos de Leibniz e discussões com outros colegas levaram a uma mudança na maneira de se pensar o fundamento leibniziano a respeito da composição dos mundos possíveis, o que tem impacto na maneira de se interpretar tanto a liberdade de Deus como a do ser humano. 
qual Leibniz elaborou a noção de substância individual, dotadas de certa independência ontológica, ainda que precisassem de Deus para se tornarem reais. Essa nova concepção de seres criados permitiu não apenas a distinção entre as ações de Deus e de suas criaturas, mas também realizou a mudança na concepção de Leibniz sobre quais seriam as unidades últimas da obra divina e em sua forma de pensar a combinação entre as partes desse plano.

Palavras-chave: Mundo; Razão; Causa; Vontade.

Abstract: This paper aims at presenting one aspect of the process of Leibniz to construct his thesis of the best of all possible worlds made by God. In his youth, the philosopher considered that the elaboration of the divine work happens by the combination of elementary parts, namely the requisites. However, that simple model of architecture puts Leibniz dangerously close to the Spinozism, in a way that God could be exclusively the source and the local where would happen the combination of the requisites. Then God could be, for example, the cause of the evil. To avoid that theological problem, Leibniz was motivated to elaborate a more sophisticated ontology focused on the notion of individual substances. Those beings have a certain degree of ontological independence, even if they need God to become real. The new conception of beings allowed not only the distinction between the God's and the creature's actions but also performed a change in the Leibnizinian conception about the latest units of the God's work and the way of the combination of the parts of the world chosen by its creator.

Keywords: World; Reason; Cause; Will.

\section{Introdução}

O mundo, para Leibniz, é arquitetado conforme o Princípio de Razão Suficiente (doravante: PRS), que é invocado ao longo de praticamente toda sua obra. Simplesmente, segundo o pensamento do filósofo, tal princípio é base para a constituição da própria realidade e inteligibilidade das coisas. Os seus textos produzidos no espírito dos seus anos de Paris (1672-1676) e seus primeiros anos em Hanover são úteis para indicar um momento crucial para a sustentação do PRS, revelando escritos determinantes para a fase madura da sua filosofia. Mesmo sem 
possuir um papel predominante, ${ }^{2}$ sua metafísica foi contemplada com escritos preciosos dessa época de juventude, dentre os quais alguns serão destacados. O primeiro deles é uma seleção de opúsculos conhecida como De Summa Rerum (Leibniz, 1992; Leibniz, 1998). Trata-se de um conjunto de textos caracterizados pela apresentação de um grande projeto de Leibniz, principalmente por envolver questões de conhecimento e método, que pode ser sintetizado pelos três programas: a enciclopédia, a ciência geral e a característica. ${ }^{3}$ Outra obra metafísica a se destacar nesse mesmo período é a Confissão do Filósofo (Confessio Philosophi/ Leibniz, 1970). Em poucas páginas desse diálogo, Leibniz não apenas apresenta questões, teses e conceitos muito ligados ao seu período em Paris, mas também uma infinidade de outros que foram incorporados em definitivo no seu pensamento futuro.

$\mathrm{Na}$ Confissão, conhecidos problemas teológicos, como aqueles a respeito da justiça divina e da autoria do mal, abrem o diálogo entre o Teólogo e o Filósofo Catecúmeno. Como Deus poderia ser a origem do mal na sua obra? Essa objeção deve ser observada mais a fundo. Vale informar que, segundo Leibniz, dentre outras provas, assegura-se que Deus é o único ser que

$2 \quad$ Foi um período em que Leibniz teve grande preocupação com as disciplinas exatas, quando ele trabalhou intensivamente na formulação do cálculo e das novas leis da dinâmica. Mas essas teses não deixaram de preparar o terreno para a sua metafísica madura (ver Mercer,1995, p.84).

3 Como afirma Rutherford: "In writings from his early Hanover years, Leibniz formulates his scheme for universal knowledge in terms of the three projects (...): the encyclopedia, which would serve as a repository for all acquired knowledge and would include a complete catalogue of the most basic concepts and principles; the general science, which would supply a method for arranging and relating the contents of the encyclopedia according to a strict logical order; and, closely associated with the general science, the universal characteristic, which would supply it with appropriate symbols, such that all the reasoning associated with the encyclopedia could be transformed into purely formal deductions, thereby ruling out the possibility of error" (Rutherford , 1998, p.101 - grifos nossos). A partir do seu método, Leibniz se esforça em tornar a metafísica uma ciência demonstrativa, a começar pelos seus fundamentos (o que havia de elementar no pensamento sobre a realidade) para, então, alcançar as verdades mais complexas (síntese). A inspiração em tal projeto se dá, sobretudo, a partir da sua ars combinatória. 
existe com absoluta necessidade, visto que no processo regressivo de busca pelas causas, ou razõesão, apenas ele se apresenta como senhor exclusivo da realidade, independentemente de qualquer outro ser. Esse argumento implica que tudo aquilo que faz parte deste mundo encontra-se na mente do criador, possuidor da máxima ciência, e existe porque o ser necessário tem o poder de criar aquilo que é apresentado pelo seu intelecto. A fonte da realidade não se encontra nas coisas mesmas, mas está numa fonte externa (Leibniz, 1992, p. 69).

Neste ponto as dificuldades começam a aparecer. Como não pensar que tal ser seja, indistintamente, responsável tanto pelas coisas boas como também pelas más? Resume-se drasticamente o problema que a Teodiceia (termo cunhado pelo próprio Leibniz) busca resolver. Todavia, essa questão tem uma armação peculiar na Confissão (ver Sleigh Jr., 1996) Antes de tudo, o texto começa com a ideia de harmonia, que significa a identidade no interior do mundo, aparentemente caótico para quem não o entender (Leibniz, 1970, p. 30-31). Tudo é abarcado pela máxima harmonia, isto é, nenhuma ação ou qualidade presentes no plano criado foge a esse conceito.

Deus e harmonia da sua obra refletem um ao outro. Como isso se dá? Ora, para Leibniz, a harmonia envolve o mundo na medida em que este é assimilado pela própria ciência divina. Tudo se mostra ao intelecto perfeito. Eis que surge a grande máxima leibniziana: "Rien n’a lieu sans raison" (Leibniz, 1970, p. 34-35). Não há nada ininteligível ou que não tenha uma causa para existir. Entretanto, ainda que a fisionomia do princípio seja semelhante à encontrada em textos mais maduros desse autor, ela não deixa de apresentar as peculiaridades dos anos parisienses. Há uma razão para tudo, pois:

Aquele que nega [que há uma razão para tudo] destrói a distinção entre o próprio ser e o não-ser. A coisa, qualquer que ela seja, que existe, terá seguramente todos os requisitos para existir. Ora, todos os requisitos para existir tomados em conjunto são a razão suficiente para existir. Portanto, tudo aquilo que existe tem uma razão suficiente para existir (Leibniz, 1970, p. 34-35 - grifos nossos). 
Nesse trecho, o PRS é associado à noção de requisito, que exige uma análise de outros textos do De Summa Rerum para ser entendido. Além de oferecer alguma luz para esclarecer os problemas envolvidos na Confissão, outros trabalhos do período de juventude de Leibniz esclarecem o que ele pensa acerca do PRS na sua estrutura elementar, mas também revelam difíceis problemas de ordem metafísica e teológica.

Embora Leibniz tivesse um arcabouço conceitual que considerasse suficiente para defender que este mundo é realmente oriundo de Deus, a partir do conceito de requisito, para não suscitar inconveniente a respeito do criador, o filósofo parece ter notado a necessidade de realizar certos ajustes na sua metafísica. A fim de apresentar parte do processo de desenvolvimento da filosofia madura de Leibniz, apresenta-se uma breve síntese do que virá nas próximas linhas. 1. Primeiramente, será investigada a noção elementar de requisito e o processo de sua combinação, conforme as características divinas destacadas na juventude de Leibniz. 2. Na sequência, será detalhada a relação entre Deus e as consequências não tão desejáveis respeito desse senhor dos requisitos que alimentam a criação da sua obra. 3. Será apresentado um problema do qual o próprio Leibniz se dá conta, o risco de uma certa proximidade com o espinosismo. 4. Por fim, para evitar tal caminho, será mostrado que Leibniz percebeu a necessidade de um aprimoramento ontológico, o que o levou ao desenvolvimento da tese das infinitas substâncias, que modificaram a maneira de representar os elementos últimos do mundo.

\section{Requisitos e combinatória}

A noção de requisito é um assunto recorrente no pensamento de Leibniz nos seus anos parisienses, em que ainda havia certo predomínio da ars combinatória. ${ }^{4}$ Vale ressaltar o ponto em que o autor afirma que a combinação suficiente de requisitos

$4 \quad$ Ver Fichant (1998, p.86). Para detalhes de ordem técnica sobre este assunto, ver Kneale (1991, p. 325-350). O importante será notar que os requisitos são inspirados pela lógica atomista (primitivae simplices)/combinatória de Leibniz. No fundo, busca-se destacar que a passagem da concepção lógica para a metafísica não está livre de problemas na sua juventude. 
(primitivae simplices) fundamenta a razão de algo, de modo que a falta de qualquer um deles impossibilita que algo exista, como observa Parkinson (in Leibniz, 1992, p. xxiii). Requisito é idêntico ao conceito de razão de algo ou à própria razão suficiente ao se tomar a somatória de todos os requisitos da coisa. Algo pode ser efetivado somente com a união das suas notas, as quais fundamentam tudo aquilo que aparece no mundo. Quanto maior o índice de essência, mais a coisa tende a existir (Leibniz, 1998, p. 21). Trata-se do primeiro modo como Leibniz esboça o critério para a distinção entre os possíveis, abrindo o espaço de disputa entre eles.

Outro detalhe que deve ser ressaltado é o fato dos requisitos não possuírem sua fonte na própria criatura, enquanto existente ou enquanto possível. Há um único suporte para todos eles, que não seria outra figura senão Deus.

Para existir, é necessário que esteja presente o agregado de todos os requisitos. Um requisito é a aquilo sem o qual a coisa não pode ser. O agregado de todos os requisitos é a causa plena da coisa. Nada é sem razão. Nada é sem o agregado de todos os requisitos. Não há razão para existir nos corpos. Isso se provaria facilmente: com efeito, ainda que se regressasse ao infinito, apenas se multiplicaria os corpos, mas não se compreenderia a razão pela qual são assim, e não de outra maneira. Para qualquer corpo dado, o agregado de todos os requisitos está fora dos corpos. O agregado de todos os requisitos de um corpo e o agregado de todos os requisitos de outro corpo estão num único e mesmo ser. Esse Ser único, qualquer que ele seja, é a razão última das coisas [...] O Ser necessário contém em si os requisitos de todas as coisas (Leibniz, 1998, p. 30 - grifos nossos).

Esta passagem sintetiza de modo extraordinário a noção de requisito e reivindica apenas uma origem para todos eles. Demonstra-se o principal modo como Leibniz procura assegurar um lugar para a figura divina nesta época. Deus seria a sede de todos os elementos que entrariam na composição do mundo. Vale entender no que resulta esse primeiro sistema combinatório, o jogo dos requisitos.

Leibniz dá a entender uma defesa de que tudo seria fundamentado a partir de certos elementos, tanto as coisas existentes quanto "as possíveis", ou seja, o mundo seria uma coleção de partes elementares indecomponíveis e condicionantes, ca- 
pazes de compor diferentes configurações. Ainda que os pensamentos e as percepções humanas não sejam capazes de detectá-los, ao menos claramente, Leibniz afirma que eles devem ser pressupostos. Apenas Deus pode abarcar, detectar e operar todos esses elementos. Em suma, tudo dependeria da associação de partículas absolutamente elementares. ${ }^{5}$

Após essa apresentação da noção dos elementae simplices, é preciso compreender as noções de possibilidade e impossibilidade na juventude de Leibniz. A ideia de impossibilidade pode se desdobrar em dois tipos (Leibniz, 1998, p. 19). No primeiro deles quando algo é absolutamente impossível. O caso de contradição expressa ilustra de maneira evidente o que seria esta impossibilidade. São situações completamente inconcebíveis, visto que portam uma contradição essencial, como "1 +2 é diferente de 3 ". Outro caso, menos explícito, ocorre quando os se toma ideias, por exemplo, como a respeito do maior de todos os números, que jamais é verdadeira (Leibniz, 1992, p. 3 ), pois mesmo o suposto maior dentre eles pode ser multiplicado por dois, o que equivaleria a considerar a parte (uma fração da série) maior que o todo (a própria série numérica), o que inconcebível. Tal caso de incompatibilidade fundamenta o conceito de impossibilidade absoluta, que se opõe ao absolutamente necessário, como Leibniz escreve em uma carta endereçada a Malebranche em 1679 (Leibniz, 1961, vol. I, p. 33; ver Leibniz, 1992, p. 3).

A outra maneira de identificar a impossibilidade é pressuposta a partir da ideia que algo se encontra fora da existência. Isso está diretamente relacionado às noções de compati-

$5 \quad$ A noção de requisito pode ser associada ao que é denominando como elementos (atributos positivos, notas ou perfeições). Através de um processo regressivo, surgem pistas sobre os requisitos. No pensamento, por exemplo, o ponto final estaria nas proposições idênticas, ou indemonstráveis, que são suficientes no que diz respeito ao campo do intelecto. Elas podem ser reduzidas a elementos mais básicos do pensar, mas isso já estaria muito além dos limites do que é cognoscível para as criaturas (Leibniz, 1998, p. 21-22; ver Leibniz, 2003, p. 190 et seq.). Na percepção, também é de se supor a presença dos elementos simples, mas eles se perdem na massa perceptiva, que capta o todo como se fosse um grande oceano, com suas partes indistinguíveis (ver Fichant, 1998, p. 85; ver Mendonça, 2013, p. 9-10). 
bilidade e de incompatibilidade dos atributos positivos, outra denominação para os requisitos. Aquilo que foi contemplado com a existência tem esse privilégio por ser mais harmônico, ou seja, existe porque contribui para o melhor acabamento daquilo que é criado. Aquilo que não é atualizado pode ser recusado não pelo fato de ter um conceito autocontraditório, mas exatamente porque não apresenta um índice de compatibilidade que o habilite a vir para este mundo, o mais rico em compatíveis. Logo, se algo não é compatível com o que foi realizado, isso significa que não combina com o estado mais harmônico, ou seja, não alcança o ápice em questão de essência. Deus é absolutamente perfeito e sede de todos (os requisitos) os possíveis. O mundo é fruto da harmonia dos seus elementos, e essa arquitetura é originada no próprio entendimento de Deus, que identifica a melhor circunscrição em meio aos atributos positivos. Se algo não se encaixa no melhor dos planos, ele é recusado pelo grande artesão, mesmo que não seja absolutamente impossível. Nesse caso, aquilo que não existe não apresenta o mais alto grau de essência. Como afirma Leibniz, a razão para algo existir ou não é a compatibilidade deste com outras coisas, o que implica também que o existente envolve vantagem em termos de realidade (Leibniz, 1998, p. 29).

No Diálogo entre Teófilo e Poliandro, datado por Grua como do final de 1670, (Leibniz, 1948, p. 258-257), Leibniz ilustra bem a ideia de compatibilidade, de incompatibilidade e da riqueza de essência. As teses sobre a necessidade e a razão da existência orientam a discussão entre as duas personagens. No início, Poliandro tende a entender que a existência deste mundo é necessária, pois ele expressa uma posição semelhante à dos estoicos, ao defender uma anima mundi, ${ }^{6}$ donde tudo é fruto da operação interna a esta. Teófilo, no entanto, argumenta que, se fosse assim, não haveria uma verdadeira razão para o existente, ou seja, não haveria uma maneira de mostrar porque as coisas são assim e não de outra forma.

Teófilo procura assegurar um critério para a existência de certas coisas em detrimento de outras, baseando-se no

6 Como será visto, o jovem Leibniz talvez não estivesse tão longe da opinião de Poliandro. 
conceito da riqueza de essência, o que combinaria com o ser perfeito. É apresentado, então, um exemplo para ilustrar esse processo (ver Fichant,1998, p. 89). Se fossem tomados os elementos possíveis A B C D E F G, igualmente perfeitos e passíveis de existir, dentre os quais fossem incompatíveis os seguintes elementos: A com B, B com D, D com G, G com C, C com F e $\mathrm{F}$ com $\mathrm{E}$, seria possível formar: quinze conjuntos compostos de dois elementos (AC, $\mathrm{AD}, \mathrm{AE}, \mathrm{AF}, \mathrm{AG}, \mathrm{BC}, \mathrm{BE}, \mathrm{BF}, \mathrm{BG}, \mathrm{CD}$, $\mathrm{CE}, \mathrm{DE}, \mathrm{DF}, \mathrm{EG}, \mathrm{FG}$ ), nove conjuntos de três elementos (ACD, ACE, ADE, ADF, AEG, AFG, BCE, BEG, BFG) e, finalmente, um conjunto de quatro elementos (ACDE). Teófilo conclui que o conjunto ACDE: "[...] será escolhido entre todos os outros, pois a partir deste obtém-se o melhor que se pode; por conseguinte, os quatro elementos ACDE serão preferidos em detrimento de BFG, que serão excluídos, pois não poderiam formar um conjunto com quatro elementos" (Leibniz, 1998, p. 286).

O ser onisciente reconhece a melhor combinação de tudo aquilo que compõe o mais belo mundo, ou seja, a mente divina reconhece a melhor armação de todos os atributos positivos. O critério para a formulação e, em seguida, para a própria criação é a simplicidade associada ao melhor resultado geral. Da mesma forma que a esfera é o sólido de maior capacidade, a composição mais simples e superior em efeitos é o alvo imediato de Deus. Logo, existir é: "ser concebido por Deus como o melhor, isto é, como o mais harmônico" (Leibniz, 1998, p. 286). Em linhas gerais, assim o jovem Leibniz apresenta o fundamento da organização das coisas. Em primeiro lugar, os atributos positivos engendram uma essência consistente, ou seja, não autocontraditória. Em seguida, a melhor junção dos requisitos, a mais harmônica, cuja identificação for puramente intelectual, seria o objeto direto da criação divina. Todavia, a própria existência de tal mundo comprova a presença do ser onisciente e onipotente, o que propicia também uma prova (mais consistente) da existência de Deus, sede intelectual dos requisitos (cf. Mercer, 1995, p. 85.) e o responsável pela melhor associação de tais itens, que existem em função dele. Eis a possível origem da legítima obra divina. 
Se o critério de compatibilidade cria limites para as coisas que podem existir, ele é um argumento ainda mais forte contra aqueles que afirmam que todo o possível seria contemplado com o decreto. Já que a totalidade dos possíveis não é totalmente compatível entre si no plano real, nem todos eles podem vir a existir (Leibniz, 1854, p. 178-179). Se todo possível existisse, não haveria motivo para afirmar a ideia de uma máxima razão, pois tudo surgiria automaticamente. Se não fosse assim, o critério de existência seria a mera possibilidade, e Deus ainda poderia ser um ente supérfluo (Leibniz, 1998, p. 29).

Não é porque A e B são possíveis individualmente que eles existem automaticamente, pois se ambos forem incompatíveis, eles não poderão existir simultaneamente. Deus se vale dessa regra. A totalidade do espaço de possibilidades não é absolutamente realizável.

Todos esses detalhes (metafísicos) são considerados importantes já em vista de uma adequação moral da figura divina. A compatibilidade-incompatibilidade está no pano de fundo do caráter louvável de Deus já em textos da época da Confissão. Há um bom tempo, Leibniz procura mostrar que a criação não é realizada indiferentemente. Há critérios envolvidos no processo que permite uma composição a partir de diferentes níveis de essência, que entram na formação de uma escala moral para as diferentes possibilidades de criação. Isso implica que deve haver diferentes valores intrínsecos às alternativas.

\section{Compatibilidade e responsabilidade}

Até aqui, foi possível traçar o panorama da estrutura metafísica do jovem Leibniz, uma espécie de primeiro atomis$m o,{ }^{7}$ ainda fortemente inspirado por uma combinatória um pouco mais simples. Foi possível ver o papel dos requisitos para a criação; isso com o auxílio das noções de compatibilidade e incompatibilidade, dois conceitos predominantes nesta fase, que se relacionam às ideias de consistência e de essência/existência. Ligado a isso, foi apresentado Deus como a sede de to-

$\overline{7} \quad$ Longe de ser idêntico à teoria das mônadas. 
dos os elementos mais simples, os componentes positivos. O intelecto divino extrai um determinado conjunto dentre eles, levando ao estado mais harmônico de coisas: o plano mais rico em essência a ser realizado.

As coisas só podem existir se alcançarem uma quantidade suficiente de combinações das suas notas. Para existirem, certas coisas devem ser compatíveis entre si, compondo, então, o mundo mais elegante. Todavia, há complicações no pensamento leibniziano no período em questão pelo fato de Deus ser a sede de todos requisitos e o responsável por reuni-los. Procurar a razão ou causa do real é ir diretamente em direção ao Criador, inclusive quando se pensa o estado harmônico do existente. Deus seria, então, a causa indistinta de tudo? Ele seria tanto causa daquilo que ocorre de bom quanto daquilo que ocorre de ruim? Isso retoma aquele problema anunciado inicialmente: Deus como o único responsável pelo mal, pois as supostas ações das criaturas se limitariam a representar uma razão do mundo (PRS), que assegura formalmente o lugar de todo fato do universo criado.

Leibniz toma um velho exemplo: a traição e condenação de Judas (Leibniz, 1970, p. 36/37). Por que este cometeu o seu grande erro? Ele realizou por si mesmo, ou o seu ato foi algo inevitável? O Filósofo Catecúmeno afirma que o discípulo de Jesus de Nazaré realizou sua má ação porque pôde e porque quis (Leibniz, 1970, p. 38-39), ou seja, Judas detinha os principais elementos que orientavam sua ação. Devido a uma inversão e a uma espécie de ódio em relação às coisas divinas, Judas teria cometido o seu erro, o que lhe fez tonar a ação digna de "escolha". Mas com aquele conceito de harmonia, tributário do PRS, que orienta o mundo, e por Deus apresentar-se como a fonte exclusiva de racionalidade, o outro personagem, o Teólogo Catequista, elabora a grande objeção do texto:

$\mathrm{O}$ pecado provém de um poder e de uma vontade. O poder vem de Deus; a vontade, da opinião. A opinião, ao mesmo tempo oriunda do temperamento e relacionada ao objeto da pessoa, provém de Deus. Portanto, todos os requisitos do pecado, assim como a razão última do pecado e todas as outras coisas, inclusive a condenação, vêm de Deus (Leibniz, 1970, p. 40-41 - grifos nossos). 
Logo, por ser a razão última das coisas, sujeito de todos atributos simples, Deus não se isentaria de ser a causa do mau, inclusive do pecado, mal de modalidade moral. Se ele é o autor da realidade, restar-lhe-ia a autoria das imperfeições inerentes à sua criação. A justificativa do Filósofo parece desintegrar-se com a argumentação do seu interlocutor. As razões da ação de Judas não estariam realmente em sua posse, pois a sede destas estaria numa fonte exterior, e não na criatura. Tanto o objeto de escolha e o ambiente do ato do discípulo já lhe aguardariam de modo fixo e intocável, sem que algo pudesse mudar a ocorrência dos fatos, ou seja, tudo estava em completo acordo com o estado harmônico. As ocorrências que aguardavam Judas se enquadravam na armação subjacente ao mundo, pensado e criado por Deus. Como aquela criatura poderia ser culpada por tal peso que caía sobre suas costas? Leibniz procura salvar a figura divina ao tentar mostrar que a sua primeira resposta, "poder e vontade em Judas", poderia ser mantida. Será que o fundamento metafísico sustentaria as pretensões morais do filósofo?

Se é justo afirmar que algumas respostas se encontram em parte delineadas na perspectiva teológico-moral na época da Confissão, não se pode dizer a mesma coisa em relação à metafísica. Para resolver essa disparidade, Leibniz luta para alcançar uma formulação filosófica que corroborasse implicações morais desejáveis, como no caso da absolvição de Deus. É preciso notar mais pontualmente, por meio da Confissão e de outros textos próximos a este, onde estariam as lacunas que precisavam ser preenchidas.

Segundo o PRS dominado pela simples somatória dos requisitos, Deus existe porque é a totalidade dos requisitos, os atributos positivos, ou seja, ele tem máxima essência. E, no fundo, indo por esse caminho, todo existente segue o mesmo princípio, não por ter a totalidade dos requisitos, como o criador, mas por se aproximar do máximo. O mundo existe porque atinge o maior grau de essência dentro da combinação dos elementos simples e, aparentemente, ganha o direito de efetivação. Há uma impressão de que a máxima inteligência identifica o plano mais rico, e de que este existe de modo imediato. Há impressão de que Deus opera internamente um mecanismo, de que 
ele praticamente se iguala a este. Vários argumentos levam à afirmação de uma forte aproximação entre harmonia e vontade (Leibniz, 1992, p. 113). Porém, haverá realmente uma vontade caso haja um sistema operatório absolutamente racional associado a Deus? Leibniz não deixa de citar conceitos como o de vontade, contingência/possibilidade e liberdade (Leibniz, 1970, p. 54-55). Teria ele direito? É preciso retroceder até a mente divina para comprovar se esses três elementos ainda participaram efetivamente da origem do mundo. Alguns pontos ainda conspiram contra os propósitos do autor.

Por meio do Teólogo, na Confissão, Leibniz entende que Deus não seria o autor do mal apenas por este supostamente identificar a presença dessa falha nas partes da obra mais harmônica. Dentro da combinação dos elementos positivos, o plano mais rico em compatíveis aparece de imediato. Mas ao contrário do criador, os próprios constituintes do mundo não alcançam o máximo em termos de essência, sobretudo quando são tomados numa perspectiva particular. Isso abre espaço para as imperfeições e, junto a elas, o mal. Assim, mesmo o melhor dos mundos possui o mal, inclusive as más ações, que além de fazer parte da estrutura desse local, o mal contribui exatamente para a principal característica da criação divina: ser a mais admirável. Assim como as sombras e as dissonâncias auxiliam a produção artística, o mal integra a mais bela obra.

Entretanto, a máxima ciência não é o único atributo de Deus. Ele é perfeito porque alcança o topo de tudo aquilo que é passível de receber um valor máximo; ele alcança o último grau naquilo que se dá a tal característica. Deus não apenas percebe o melhor, como também apresenta a tendência de efetivar o melhor em função do tipo de Ser que é. O estado de harmonia do mundo também reflete Deus, pois o estado de perfeição daquele espelha a onisciência deste. Há um jogo de reciprocidade da razão entre Deus e sua obra criada. É peculiaridade da natureza divina ligar-se ao que há de perfeito. E se isso ocorre pelo lado de Deus, isso deve valer para o oposto, ou seja, se este mundo não for como tal, o mais harmônico, inclusive com a presença do mal, isso pode significar que o seu arquiteto é outro, e não Deus. Esse seria um argumento robusto, visto que 
é de forte inspiração lógica, nos moldes do modus tollens: se a existência de $A$ implica a existência de $B$, a não existência de $B$ implica a não existência de $A$ (Leibniz, 1970, p. 46-47).

A vontade divina não participaria efetivamente na elaboração da criação? Tudo apareceu apenas porque Deus existe? Como Deus poderia realmente querer algo diferente? Com a argumentação acima, novamente se torna difícil sustentar a presença da sua vontade, o que não permitiria a ideia de uma origem moral do existente. Deus não criou tudo aquilo que seria possível, mas tudo aquilo que existe parece ter sido a única coisa a se criar. Pode-se dizer que a totalidade do espaço de possibilidades não é realizável - o princípio de compatibilidade e incompatibilidade e o próprio princípio de não contradição asseguram isso - , mas aquilo que não foi efetivado ainda não deveria receber a denominação de possível. O intelecto e o poder divinos não deixariam tanto espaço para o seu querer. Além disso, no mínimo, caso a vontade fosse concebível, ela seria "arrastada" pelo entendimento. Ao final, bastaria ao mundo ser orientado exclusivamente pelo princípio da harmonia dos requisitos que integram a obra realmente divina (Leibniz, 1970, p. 64-65).

As coisas complicar-se-iam ainda mais. Por exemplo, Judas ainda poderia ilustrar a responsabilidade das criaturas? Não seria necessária a ocorrência da traição? Em contraposição a isso, Leibniz busca até moderar o peso da necessidade por meio da necessidade alterius hypothesis. Como se pôde notar, por não possuírem uma razão em si mesmas, as criaturas dependem de uma razão externa, ou ser de existência necessária, que garanta a estruturação e a existência do mundo.

É falso que tudo aquilo que se segue do ser necessário em si também seja necessário em si. É certo que a partir de proposições verdadeiras se siga apenas o verdadeiro. [...] Das coisas existentes não se segue necessariamente senão Deus. Todo o resto que se segue da série de coisas supostas, ou seja, da harmonia das coisas ou da existência de Deus, é contingente em si ou apenas hipoteticamente necessário. Embora não haja nada fortuito, visto que tudo decorre do destino, isto é, de uma razão determinada da providência (Leibniz, 1970, p. 54-55 - grifos nossos). 
Surgiria assim a conhecida tese de Leibniz referente a dois tipos de necessidade, uma em si e outra hipotética. É sabido que o segundo modelo de necessidade depende da realidade necessária de uma causa, porém ela não parece sair ilesa da objeção anterior pelo fato das criaturas não causarem a si mesmas. Elas acabam por receber um destino inflexível, que as acompanha desde a origem do mundo (e dizer que para tudo há um destino não facilita as coisas). A transitividade de necessidades seria inevitável, pois quando há identificação estritamente intelectual de uma opção, o estado mais harmônico, que constrange Deus a criá-la em vista da perfeição, tudo o que está no interior de tal alternativa não deixaria de se efetivar de uma forma absoluta. Os próprios requisitos bastam para engendrar a existência. Ao final, e este é o grande problema a ser resolvido: o que a onisciência mostra é o que será realizado, sem que haja a intervenção de uma verdadeira escolha.

As ações das criaturas corroboram a composição da realidade da pior maneira para elas e inclusive para Deus. O mundo é o que é porque elas são necessariamente de tal e tal forma, antes mesmo do decreto. Para adiantar outro detalhe, os objetos almejados e as supostas disposições daquelas são constitutivos da ordem das coisas. Seria, então, o fim da liberdade? Não é o que Leibniz procurou mostrar. Pelo contrário, elas deveriam agir como quisessem, ainda que estejam numa série totalmente arrematada. As ações também ocorrem em meio às coisas existentes devido à presença suficiente dos requisitos. Como Deus tem acesso a todos os atributos positivos, ele conhece cada ação e sabe que todas fazem parte deste plano harmônico.

Ainda na Confissão, o Teólogo quer entender como poderia haver liberdade junto à máxima ciência divina. Então, num último esforço, ele lança um grande dilema. Frente a frente com Deus, o que ocorreria se o perguntasse: "para qual direção moverei meu braço" (Leibniz, 1970, p. 70-71)? Se ele apontasse para um lado e o movimento realizado fosse diferente, a liberdade estaria assegurada, mas Deus não seria mais perfeito. Se o movimento fosse absolutamente aquele que Deus apontou, sua perfeição seria conservada às custas da liberdade 
da criatura. "Ou a pré-ciência ou a liberdade é suprimida" (Leibniz, 1970, p. 72-73).

Continuando a passagem sobre "o movimento do braço", o Teólogo afirma ser livre na medida em que pode fazer um movimento diferente do previsto e afirmado por Deus. O Filósofo Catecúmeno, insatisfeito com tal resposta, acrescenta o seguinte:

Esta sutileza é ardilosa, mas, de todo modo, ela não resulta senão nisso: a alma que seria desta natureza, que queira e possa fazer ou querer o contrário daquilo que poderá ser previsto por qualquer um, é do número de entes que são incompatíveis com a existência do Deus onisciente, ou seja, com a harmonia das coisas e, por conseguinte, que não existiram, nem existem, nem existirão (Leibniz, 1979, p. $72-73$ - grifos nossos).

Logo, tudo indica que o tom final da resposta é dado pelo mesmo jogo dos requisitos da arquitetura apresentada pelo jovem Leibniz. Apesar de referir-se à vontade das criaturas, esta não está apartada da soma dos atributos positivos. A existência depende apenas do grau das essências, o mesmo ocorrendo no caso das ações, sem que haja "preferência" por qualquer coisa. Se algo é feito por tal criatura, é porque houve a convergência de certos atributos, que estão de acordo com o estado harmônico deste mundo, o melhor e, consecutivamente, o existente.

\section{O reconhecimento do problema}

Após algum tempo, Leibniz tomou consciência dos riscos que estava correndo. No texto De Libertate, ele próprio revela que não estava no caminho certo para associar a liberdade ao PRS nos moldes dos textos da época da Confissão.

Da minha parte, na época em que considerava que nada se faz ao acaso ou por acidente, se isso não é relativo a certas substâncias particulares, que a fortuna separada do destino não passa de um nome vazio de sentido e que nada existe a não ser quando são dados os requisitos singulares (ora, segue-se desses requisitos, quando todos se associam uns aos outros, que a coisa existe), eu estava pouco distante da opinião daqueles que julgam que tudo é absolutamente necessário, bastando que a liberdade fosse preservada do constrangimento, ainda que permanecesse submetida à necessidade, sem distinguir o necessário do infalível, ou seja, do verdadeiro, quando se conhece a coisa com certeza (Leibniz, 1998, 329 - grifos nossos). 
O resultado disso para a liberdade, principalmente a divina, seria sua redução a praticamente dois dos seus ingredientes: inteligência e espontaneidade (talvez nem isso no caso das criaturas). Bastaria a convergência de certos elementos e a falta de qualquer empecilho para a ação. Eis o que seria o critério geral de existência e, portanto, das ações das criaturas. $\mathrm{Na}$ continuação dessa passagem, Leibniz afirma que foi retirado do abismo em que estava prestes a cair por oferecer uma verdadeira cidadania aos possíveis não realizados.

A Confissão apresenta avanços ao delinear claramente as principais pretensões de Leibniz acerca da liberdade, além de uma teodiceia, embora sem mostrar tal paridade entre suas intenções e o arcabouço metafísico. Naquele texto, o filósofo não mostra ir muito além, por exemplo, do que é escrito a Wedderkopf, carta de 1671 (Leibniz, 1969b, p. 146-147; ver Adams, 1993, p.129-130), em que, mesmo a contragosto, a necessidade absoluta se mostra inevitável para Deus. Nessa mesma carta, Leibniz apresenta uma ideia de liberdade com toque fortemente intelectualista. Não realizar o melhor seria fruto de ignorância ou fraqueza. Essa é a forma que ele encontrou para combater a liberdade caprichosa ou voluntariosa. No caso de Deus, não haveria outra saída: Ele tem posse da melhor obra, identifica-se com ela e é impossível que realize outra em seu lugar. A partir desse raciocínio, a obra oposta é tomada apenas enquanto discurso vazio, e não como legítima alternativa, mesmo com a postulação daquela segunda incompatibilidade. Seria inconcebível cogitar qualquer coisa que arranhasse o ser perfeito: se ele visse o melhor, mas sem realizá-lo, isso seria sinal de fraqueza, fazendo-o perder a onipotência. Caso não ponderasse tudo previamente, criando qualquer coisa, não seria onisciente. Em poucas palavras: se não faz o melhor, não é Deus.

A partir de tais problemas, Leibniz vê-se obrigado mostrar que a realidade não é idêntica a um processamento interno ao seu artífice (sujeito de todas as perfeições), ou um mero combinador, em que os diferentes níveis de essência implicam uma realidade imediata, ou seja, onde apresentar-se como o melhor é idêntico a ser decretado. Também há necessidade de assegurar um verdadeiro modelo de ação das criaturas, única 
maneira de mostrar que elas não são meros acidentes, mas contribuem para o resultado do mundo como verdadeiros agentes. É preciso encontrar junto a Leibniz a via para garantir a ideia de moralidade na própria origem do mundo e no próprio interior deste local, pois Deus ainda estaria reduzido à onisciência e à onipotência. Novos detalhes devem ser acrescentados no intuito de garantir a vontade de Deus e para comprovar que as criaturas tenham poder sobre suas ações.

A soma suficiente dos requisitos e o forte teor intelectualista, a despeito da presença da tese do plano mais harmonioso comparado a outros possíveis, não foram as melhores soluções, suscitando aquele grande problema moral: Deus como causa indistinta de tudo, inclusive daquilo que há de ruim. Todas as ações no mundo seriam absolutamente originadas a partir do encontro suficiente dos atributos positivos, sediados no intelecto divino, que se aliaria apenas à onipotência nessa composição. O único responsável nessa história seria o próprio criador. Na Confissão, o autor procurou mostrar que Deus não participaria do mal por não ser causa imediata deste, e sim as criaturas. São nítidas as dificuldades em tal afirmação, pois como foi visto, tomar Deus como causa da totalidade das coisas, por um lado, e limitar esse poder, por outro, não seria algo muito viável, principalmente no campo dos atributos positivos. Tornou-se difícil sustentar que Deus é causa apenas do bem. Enquanto construtor do objeto mais harmônico, Deus não seria muito diferente daquele ser uno, para quem tudo não passaria de sua operação interna, sem que as legítimas ideias de vontade e de possibilidade fossem garantidas. Segundo Leibniz, no fundo, ele estaria perigosamente próximo do espinosismo.

A substância espinosista não abre espaço para a afirmação de outra(s) substância(s), e tudo se reduz às simples modificações daquela. O homem, por exemplo, seria formado pelo modo pensamento e pelo modo extensão. Segundo a interpretação leibniziana, na Ética de Espinosa, os homens não têm uma substancialidade própria ou particularizada, mas apenas participam da totalidade do mundo, onde a substância se encontra imanente. Seria um erro falar em seres. Fora o único ser, 
há apenas os desdobramentos da única substância ou meros acidentes, entende Leibniz.

Leibniz passa a procurar uma via para distinguir as ações das criaturas em relação à sua fonte de realidade. Ele entende que é visível no caso da substância una espinosana a não separação entre as ações desta e as ações dos modos, pois seriam um único e mesmo ato, ou seja, tudo seria interno ao único ser. No sistema espinosista, as ações são originadas da própria autorrealização da substância, que também pode ser denominada como Deus. Mas, como afirma Gaudemar (In: Leibniz, 1999, p. 73), assim como para os escolásticos, para Leibniz, a existência deve ser um efeito fora da causa. ${ }^{8}$

Outro detalhe, criticado por Leibniz, acerca do Ser espinosista é a sua não operação a partir de um campo de possibilidades, visto que tudo aquilo que existe não deixa de ser único; se é "possível", não deixará de ser real. Para Espinosa, a tese sobre algo presente na mente divina já é portadora de realidade de modo semelhante às propriedades que derivam do conceito de uma figura geométrica, como o caso triângulo, que necessariamente tem três lados, por exemplo. Ser uma ideia em Deus implica imediatamente existir (ver Gaudemar, in: Leibniz, 1999, p. 70). Não há possíveis (não realizados) para Deus, não fazendo sentido atribuir-lhe a vontade, que não passaria de um atributo ilusoriamente criado pelas mentes fantasiosas das criaturas. Deus possui apenas poder e intelecto, sem vontade. Ele não precisa ponderar entre vários caminhos possíveis de criação. Basta algo vir-lhe à mente para que tal objeto seja contemplado com a realidade.

Embora não parecesse, o próprio Leibniz veio a considerar que ele estava muito próximo das características do seu oponente em meados de 1670. Ainda que as ideias de um Deus extrínseco ao mundo e a de possibilidade fossem de certa forma postuladas, ele viu parte do pensamento do judeu ateu invadir o sau própria filosofia. A carta endereçada a Wedderkopf (Leibniz,

Leibniz ainda acrescenta que: "Deus existe necessariamente, mas ele produz livremente as coisas. Deus produziu a potência das coisas, mas ela é distinta da potência divina. As coisas operam elas próprias, ainda que tenham recebido as forças para agir" (Leibniz, 1999, p. 27). 
1969b, p. 146-147) expressa em parte essa característica. Ainda que houvesse a referência a diferentes alternativas para Deus, ao se deparar com o melhor, ele não teria outra (verdadeira) opção que criar o objeto do seu intelecto, sem que pudesse fazer diferente. O melhor mundo seria praticamente idêntico a Deus, e novamente entende-se que qualquer alteração naquele poderia acarretar uma mudança no conceito do seu criador.

Todavia, como também é afirmado por Gaudemar (in: Leibniz, 1999, p. 79), Leibniz busca provar que há uma diferença entre o fiat possível, obtido pelo cálculo, e o fiat efetivo, de modo que haja uma diferença entre o resultado da ponderação divina e a decisão de criar.

Mas como Leibniz busca superar os problemas oriundos da sua fase da simples combinação dos requisitos? Ele afirma que foi resgatado do precipício quando realmente incorporou os genuínos objetos possíveis ao seu sistema (Leibniz, 1998, p. 329-330). Mesmo as coisas não coroadas com o decreto deveriam permanecer verdadeiramente possíveis. Mas para sustentar isso, seria preciso remodelar os componentes do mundo.

\section{A entrada em cena das substâncias}

Leibniz entende que fora salvo daquela espécie de necessitarismo, oriundo do puro jogo dos requisitos, devido às infinitas substâncias. Como foi visto, os elementae simplices eram operados apenas por Deus, no seu intelecto. Ao final, o melhor plano (adequado à perfeição geral divina) não oferecia alternativa legítima senão a sua efetivação. A elaboração do conceito de substância criada, inicialmente denominada como substância individual e, algum tempo depois, como mônada, teve como motivação uma arquitetura mais apropriada para o melhor dos mundos.

É possível começar a entender os motivos das mudanças realizadas no campo metafísico ao serem observadas exatamente as críticas endereçadas a Espinosa. Embora, seja um texto quase do final da sua vida, em uma correspondência enviada a Bourguet, em dezembro de 1714, Leibniz resume como 
conseguira distanciar-se de qualquer acusação de espinosismo devido ao seu conceito de substâncias, distinto do monismo (Leibniz, 1961, vol. III, p. 575). Em oposição à única substância de modelo espinosista, da qual tudo seria ontologicamente indistinto, Leibniz passa a defender que existem infinitas substâncias, verdadeiros seres. A crítica seria basicamente a seguinte: "[Espinosa] teria razão caso não houvesse de maneira alguma as mônadas. Se assim fosse, tudo aquilo que estivesse fora de Deus seria passageiro e se esvaneceria em simples acidentes ou modificações, pois não haveria qualquer base para as substâncias nas coisas, a qual consiste na existência das mônadas" (Leibniz, 1961, vol. III, p. 575 - grifos nossos).

Nesse trecho, de um momento ainda mais avançado da filosofia de Leibniz, ele se vale do termo mônada, introduzido na última etapa da sua ontologia. Entretanto, o conceito de mônada serve para indicar o salto que houve no pensamento leibniziano acerca das componentes do mundo, já indicadas em textos da época do Discurso de Metafísica, posteriores à sua juventude. Embora seja sabido que há certas distinções entre a substância em textos da fase do Discurso e da fase da Monadologia, há certas teses ontológicas que atravessam fases distintas do pensamento maduro leibniziano, e é isso que será importante levar em conta. ${ }^{9}$

Leibniz notou a necessidade de criar um espaço de equilíbrio entre o ser divino e os seres criados, sem a ocorrência de um conflito entre os dois campos. Assim, ele encontrou uma saída nas infinitas substâncias ou como se encontra no oitavo artigo do Discurso: "Para distinguir as ações de Deus e das criaturas, explica-se em que consiste a noção de uma substância individual" (Leibniz, 2004a, p. 16-17). Os seres possíveis individuais foram o marco para que as criaturas deixassem de ser meros acidentes.

Uma das primeiras teses para a construção do conceito de substância se deu a partir da noção completa, classicamente apresentada na seção VIII do Discurso de Metafísica. A noção completa, inicialmente de inspiração lógica, baseava-se na tese

Para uma comprensão específica da variação do conceito leibniziando de substância, ver Fichant (2000). 
dos seres considerados como sujeitos últimos. A base disso está em três princípios. O primeiro, o de in-esse, que indica que todo predicado está contido na noção do sujeito da proposição verdadeira. O segundo, que uma substância é representada como o sujeito de predicados sem que ela mesma seja predicado de qualquer outro sujeito. Por fim, que uma substância é representada por um sujeito que possui a totalidade dos seus predicados, pois se tivesse uma única predicação em aberto, ela poderia ter seu conceito atribuído a outro sujeito. Para ilustrar isso, Leibniz se vale dos exemplos de Alexandre Magno e rei (Leibniz, 2004a, p. 17), pois aquele personagem é realmente um ser individualizado, que não pode ser predicado de qualquer outra coisa. Já no caso de rei, embora tenha certos predicados que o definem, pode vir a ser predicado de outro sujeito, por exemplo, do próprio Alexandre. Com sua noção absolutamente completa, em função da posse de todos os seus predicados, cada substância passa a ser entendida como uma legítima unidade. Todo o ser passa a ser definido em termos de completude de sua noção, seja existente, seja possível. Deus identificaria perfeitamente cada um desses sujeitos últimos, doravante substâncias.

Como é sabido, há várias implicações a respeito das substâncias (Leibniz, 2004a), com destaque para a: a máxima distinção entre tais seres, sua perenidade, a espontaneidade interna a cada uma e, a se destacar, a compossibilidade entre elas. Tudo isto oferece o novo tom da arquitetura elaborada pelo criador. Nota-se o caminho traçado por Leibniz no sentido de assegurar a ação das criaturas e uma ideia consistente de vontade em Deus; lembrando que esta deveria ser descontaminada do risco de ser causa do mal.

Leibniz passa a considerar que, embora real, o arbítrio de Deus não participa de modo ilimitado e equivocado na constituição dos infinitos seres. Apesar das fortes diferenças entre duas teses ontológicas, tomar o mundo como composto por substâncias de noção completa e em parte autônoma lembra o jogo dos requisitos (níveis de essência) do jovem Leibniz, já que a substância individual é pensada, num primeiro momento, em termos intelectuais. Não obstante, independentemente de Leibniz já ter pensado numa dimensão de pura inteligência, 
onde há combinação dos possíveis, a concepção de substâncias criadas possibilitou muitos avanços.

Já pode ser notado que o PRS não será mais oriundo de uma matriz apenas intelectual. O grande passo é mostrar que também há uma participação de uma vontade na origem das coisas, sem que ela seja a única que domine a produção de tudo, como no cartesianismo (ver Santos, 1998, p.100-101). Logo, as infinitas substâncias já mostram a sua primeira função: colocar a vontade divina no seu devido lugar, sem renegar sua máxima ciência.

[D]igo, portanto, que a relação entre Adão e os eventos humanos não independe de todos os decretos livre de Deus, mas também que aquela não depende completamente disto de maneira indistinta, como se cada evento ocorra ou seja previsto apenas em virtude de um decreto particular primitivo que objetiva o fato (Leibniz, 1961, vol. II, p. 40).

A vontade divina é focada em efetivar aquilo que o seu intelecto lhe apresenta: conjuntos de possíveis detalhadamente armados, dentre os quais um pode vir a ser decretado conforme o seu valor em relação aos restantes ou se for o melhor. Leibniz considera esse tipo de vontade como satisfatória e adequada para Deus, ao mesmo tempo em que mostra que o criador não concebe as coisas de modo fragmentado, e sim de um modo que combina com o seu intelecto. Ele também pode mostrar que Deus tem um verdadeiro espaço de volição, não de coisa por coisa, mas há eleição em meio a blocos possíveis. Mas o que significam tais blocos?

Cada substância reflete exclusivamente o mundo do qual participa, ou melhor, é compossível em relação aos outros seres que o compõem (LEIBNIZ, 2004b, p. 141). A compatibilidade dos requisitos dá espaço para compossibilidade entre as substâncias, pois Leibniz entende que cada uma dentre elas já possui tudo no seu interior, e, logo, cada uma reflete as noções das outras substâncias com as quais participa do grande teatro do mundo. Em suma, como as coisas não se apresentam de modo desconexo à mente divina, mas na forma de vários conjuntos possíveis de seres, em função da noção de substância individual, Deus opta 
por um desses blocos de substâncias (Leibniz, 1969, vol. II, p. 41). Isso pode também gerar a impressão de uma imposição das coisas à vontade divina, mas de fato poderia amenizar o processo do simples jogo dos requisitos. As substâncias possuem noções integrais e portam a compossibilidade no seu íntimo, sem que Deus precise pensar e criar coisa por coisa.

Um detalhe que Leibniz passa a ressaltar na sua fase madura é a característica divina de não tomar decisões isoladas, visto que Deus opta por criar (ou simplesmente refletir) as substâncias num conjunto que lhes é próprio. Ele não realiza o mundo de maneira miraculosa, ou seja, não toma decisões em paralelo aos acontecimentos, o que também só se sustenta a partir da ontologia das diversas substâncias. Como ele identifica os conceitos fora do tempo (Leibniz, 1969, p. 251; ver Santos, 1998, p. 96 e 111.), de modo imediato, Deus não precisa tratar cada uma das substâncias isoladamente, mas todas juntas e em harmonia. Por exemplo, não é porque Deus optou por Adão, neste mundo, que tudo seguirá a partir da noção desta criatura, como se as coisas fossem pensadas apenas em função de um item inicial, de modo que uma sequência se siga deste. Se o futuro está assegurado após a criação do primeiro homem, é porque todas as outras personagens envolvidas no destino de Adão também foram objetos de uma reflexão prévia e simultânea.

Como o próprio Leibniz exemplificou, Deus é como aquele príncipe sábio que opta pelo melhor general, não apenas pelo fato da competência deste, mas também porque um bom general optará por bons coronéis e bons comandantes para o exército que lhe será incumbido (LEIBNIZ, 1969, vol. II, 19). Logo, a escolha do príncipe não se limitaria a uma, mas encadearia algo muito mais amplo, igualmente como ocorre na mente de Deus. Vale acrescentar que cada substância é tomada em função do seu conceito, que lhe é próprio, inclusive pelas suas ações; isso lhe atribui lugar peculiar no mundo que ela integra.

\section{Considerações finais}

Ali, em meados dos anos parisienses, Leibniz estava muito ligado à região da compatibilidade e incompatibilidade no 
sentido estrito (Fichant, 1998, p. 111), praticamente neutralizando a volição divina. Como foi visto, tudo indica que a vontade de Deus tem lugar assegurado exatamente junto à configuração da região dos compossíveis, espaço assegurado através das infinitas substâncias, apesar de haver certo destaque ao intelecto divino. Além de participar da efetivação do melhor mundo, que é o seu ponto alto, a vontade não está totalmente apartada da armação do universo. Num primeiro momento (não em termos temporais), independentemente da tendência de um plano ser elegível a priori, como qualquer outro, o melhor dos mundos possíveis deve ser concebido na mente divina apenas como possível. Isso não era completamente garantido a partir da simples combinatória dos requisitos, que antes já tendia para o resultado mais harmônico e que engendrava uma existência imediata (ainda mais com o império absoluto do intelecto divino). ${ }^{10}$

$10 \quad$ Gueroult tende a considerar que há certa base de elementos simples num jogo combinatório mesmo nas fases mais maduras do pensamento leibniziano, de forma que haveria uma diferença entre as essências, que seriam espécie de proto-seres, tomados isoladamente, e as substâncias propriamente ditas, quando surgiriam as noções completas e, por conseguinte, a compossibilidade (Gueroult,1946, p. 298-299). Não há condições de avaliar toda a proposta interpretativa de Gueroult. De qualquer modo, embora a tese desse estudioso pareça ser respaldada por textos da fase intermediária de Leibniz, que inclui textos como o Discurso de Metafísica e as correspondências desse filósofo com Arnauld (Leibniz, 1961, vol. II), em que há certa distinção entre os seres tomados do ponto de vista essencial (sub ratione generalitatis) e do ponto de vista substancial (sub ratione possibilitatis), é de se questionar se a posição de Gueroult se sustenta ao se tomar textos da época da Monadologia e dos Princípios da Natureza e da Graça, quando a substância, doravante mônada, é considerada um átomo genuíno.

Já Fichant (1998) parece notar maior distinção, ao menos indiretamente, entre os textos de juventude e os de maturidade de Leibniz a respeito do arranjo do mundo. Em parte, Fichant tende a considerar a presença latente da combinatória dos elementae símplices, ainda na fase madura de Leibniz, mas também as suas complicações. Por exemplo, há problemas em conciliar o fato de Deus sediar todos esses elementos ou requisitos, de modo que sejam todos compatíveis neste caso, e defender certa incompatibilidade entre eles no caso da composição dos mundos possíveis. Nesse ponto é que há certo salto de Leibniz na formulação das substâncias como os elementos últimos da realidade e o predomínio da compossibilidade sobre a compatibilidade. Embora se identifique certo gap entre o mundo composto pelos requisitos e o mundo composto por substância, o que prevaleceu na filosofia de Leibniz foi o melhor dos planos composto por um conjunto de infinitas substâncias. 
Leibniz busca conciliar certa independência das noções das substâncias integrantes do mundo e a compreensão desses respectivos conceitos pelo criador, que escolhe o objeto que o reflete. O Deus leibniziano tem certo índice de vontade, mas não se igula ao Deus cartesiano. No caso deste, a criação fica incumbida à vontade sem limites; no daquele, o decreto ainda tem o máximo intelecto como eixo principal (não exclusivo).

É fato que Deus deve agir do modo que melhor lhe convém, enquanto ser perfeito. Antes, parecia que o intelecto e o máximo poder eram suficientes para representar o criador, mas isso não combinaria com o criador leibniziano. Partir do princípio do "ver o melhor e, caso nada impeça, realizá-lo" não permitia um julgamento moral da obra divina. A criação não passaria de um processo automático. A partir das infinitas substâncias, é possível afirmar a presença de um campo de possibilidades, detectadas pelo intelecto, que se apresentam ordenadamente à vontade divina em função dos seus graus de essência, ou de riqueza ontológica. Como o criador é predisposto a perseguir o melhor, devido à sua bondade, ele busca aquilo que está no topo dessa escala de possíveis: o melhor. Portanto, o PRS não se limita à associação entre conhecimento e poder. Como bem aponta Leinkauf (2003, p. 273), o mundo criado depende não apenas de uma razão lógica, mas também de uma razão moral. Portanto, viu-se o processo que levou a filosofia de Leibniz a defender uma arquitetônica, cuja ilustração se encontra no seu célebre mito de Sextus Tarquinius, apresentado no final da Teodiceia (Leibniz, 1969, p. 354 et seq.).

\section{Referências}

FICHANT, M. Science et métaphysique dans Descartes et Leibniz. Paris: PUF, 1998.

FICHANT, M. Da Substância Individual à Mônada. Analytica, vol.5, n¹-2, 2000, p. 11-34.

GUEROULT, M. Substance and the primitive simple notion in the philosophy of Leibniz. Philosophy and Phenomenological Research, Vol. 7, No. 2, 1946, p. 293-315 
LEIBNIZ, G. W. De Summa Rerum, Metaphysical Papers 1675-1676. Translated with an introduction and notes by G.H.R. Parkinson. New Haven and London: Yale University Press, 1992.

LEIBNIZ, G. W. Die Philosophischen Schriften von Gottfried Wilhem Leibniz, 7vols. Ed. Karl Immanuel Gerhardt. Hildeshein: Olms, 1961.

LEIBNIZ, G. W. Discurso de Metafísica. In: LEIBNIZ, G. W. Discurso de Metafísica e otros escritos. Apresentação e notas de T. M. Lacerda. São Paulo: Martins Fontes, 2004a.

LEIBNIZ, G. W. Escritos Filosoficos. Ed. Ezequiel de Olaso. Madrid: Machado Libros, S/A, 2003.

LEIBNIZ, G. W. Essais de Théodicée. Ed. J. Brunschwig. Paris: Garnier-Flammarion, 1969a.

LEIBNIZ, G. W. Lettres et opuscules inédits de Leibniz, précédées d'une introduction par A. Foucher de Careil. Paris, 1854. Disponível: https://gallica.bnf.fr/ark:/12148/bpt6k64857b/f4.item.zoom [acessado em: 13/04/2019].

LEIBNIZ, G. W. Monadologia. In: LEIBNIZ, G. W. Discurso de Metafísica e otros escritos. Apresentação e notas de T. M. Lacerda. São Paulo: Martins Fontes, 2004b.

LEIBNIZ, G. W. Nouveaux Essais sur l'Entendement Humain. Ed. J. Brunschwig. Paris: Garnier-Flammarion, 1966.

LEIBNIZ, G. W. Philosophical papers and letters. Ed. e Trad. L. E. Loemker. Dordrecht- Holland: D. Reidel Publishing Company, 1969b.

LEIBNIZ, G. W. Recherches générales sur l'analyse des notions et des vérités 24 thèses métaphysiques. Ed. Michel Fichant. Paris, PUF, 1998a.

LEIBNIZ, G. W. Réfutatio inédite de Spinoza. Lecture et appareil critique de M. de Gaudemar. Paris: Babel, 1999.

LEIBNIZ, G. W. Textes inédits : d'après les manuscrits de la Bibliothèque provinciale de Hanovre. Ed. G. Grua. Paris: PUF, 1948 (1998).

LEINKAUF, T. Gottfried Wilhelm Leibniz - Transformação sistemática da substância: unidade, força, espírito. In: Kreimendahl, L. (org.), Filósofos do século XVII. São Leopoldo (RS): Editora Unisinos, 2003.

MADOUAS, S. L' Adam vague et la constituition des mondes possibles: une pensée de l'individu. In: Berlioz, D. (ed.). L' Actualité de Leibniz: Les Deux Labyrinthes. Studia Leibinitiana Supplementa. Stuttgart, Franz-Steiner Verlag, n³4, 1999, p. 363-388.

MENDONÇA, M. 2013. O estatuto da causa final em Leibniz. Cultura [Online]. Vol. 32. p. 1-18. Disponível: https://journals.openedition. org/cultura/2008 [acessado em: 15/04/2019]. 
MERCER, C. and SLEIGH JR., R. C. The early period to the Discourse on Metaphysics. In: Jolley, N. (ed.). The Cambrige Companion to Leibniz. San Diego: Cambridge University Press, 1995.

RUTHEFORD, D. Leibniz and the rational order of nature. Cambridge University Press, 1998.

SANTOS, L. H. L. Leibniz e a Questão dos Futuros Contingentes. Analytica, vol.3, n²1, 1998, p. 91-121.

SLEIGH JR, R.C. Leibniz's First Theodicy. Philosophical Perspectives, 10, Metaphysics, 1996, p. 481-499. 